\title{
Child abuse, dissociation, and core beliefs in bulimic disorders
}

\author{
Joanne Hartt ${ }^{\mathrm{a}}$, Glenn Waller ${ }^{\mathrm{b}, *}$ \\ ${ }^{a}$ Department of Psychology, University of Southampton, Southampton, UK \\ ${ }^{\mathrm{b}}$ Department of Psychiatry, St. George's Hospital Medical School, University of London, \\ Cranmer Terrace, London SW17 ORE, UK
}

Received 26 August 1998; received in revised form 18 December 2001; accepted 27 December 2001

\begin{abstract}
Objective: This study of bulimic women examined the relationship between the severity of four forms of reported child abuse (emotional abuse, neglect, physical abuse, sexual abuse) and bulimic pathology. In addition, it investigated the relationship of abuse with dissociation and core beliefs.

Method: A sample of 23 women with bulimic disorders completed standardized self-report measures of child abuse, dissociation, core beliefs, and bulimic symptomatology. They also completed diary records of bulimic behaviors.

Results: No dimensional relationship was found between any form of child abuse and bulimic pathology. However, within this group of bulimics, neglect and sexual abuse were correlated with dissociation. In addition, a subset of core beliefs was associated with child abuse, with different cognitive profiles associated with each form of trauma.

Conclusions: The findings need to be interpreted with caution because of the small, heterogeneous sample involved. Further research involving larger, homogenous samples is needed to investigate the generalizability of these findings, in order to determine if particular abusive experiences and core beliefs need to be addressed therapeutically in such cases. In addition, future research should consider the relationships between abuse, core beliefs and other impulsive behaviors.

(c) 2002 Elsevier Science Ltd. All rights reserved.
\end{abstract}

Keywords: Childhood abuse; Core beliefs; Bulimia; Dissociation

${ }^{*}$ Corresponding author. 


\section{Introduction}

The relationship between child abuse and eating disorders has been the subject of much theoretical and research interest (e.g., Root \& Fallon, 1988, 1989; Rorty, Yager, \& Rossotto, 1994; Steiger \& Zanko, 1990). Empirical studies examining whether child abuse is a risk factor for the eating disorders have mainly concentrated on the area of sexual abuse. Investigators have found a high prevalence of reported sexual abuse in women with eating disorders (Hall, Tice, Beresford, Wooley, \& Hall, 1989; Oppenheimer, Howells, Palmer, \& Chaloner, 1985; Waller, 1991). However, controlled studies have not found a specific link between these two phenomena (Folsom et al., 1993; Steiger \& Zanko, 1990; Vize \& Cooper, 1995). Consequently, it has been argued (e.g., Connors \& Morse, 1993) that sexual abuse is best regarded as a nonspecific risk factor within the context of a multifactorial model of the development and maintenance of eating disorders (e.g., Slade, 1982).

When different types of eating disorder are considered separately, there is evidence of a stronger association between sexual abuse and bulimic disorders than with restrictive anorexia (Fullerton, Wonderlich, \& Gosnell, 1995; Steiger \& Zanko, 1990; Waller, 1991; Waller, Halek, \& Crisp, 1993). Moreover, while the presence of sexual abuse has not been shown to be a specific risk factor for bulimic disorders (e.g., Garfinkel et al., 1995; Welch \& Fairburn, 1994), research indicates that a more refined relationship may exist between the severity of sexual abuse and severity of bulimic pathology (Abramson \& Lucido, 1991; Hastings \& Kern, 1994; Waller, 1992). For example, Waller (1992) found that more severe abuse characteristics (e.g., abuse involving force or a family member) were associated with a higher rate of bulimic behaviors in a clinical sample. However, two subsequent studies involving clinical samples have reported no such association (Sullivan, Bulik, Carter, \& Joyce, 1995; Vize \& Cooper, 1995). The differences in these findings may be due to methodological differences. While the study by Waller (1992) used diary records to determine frequency of bulimic behaviors, the subsequent studies relied on self-report, which is argued to be less reliable (Fahy \& Eisler, 1993).

Functional models of bulimic behaviors suggest a way of understanding such a link between abuse and bulimic behaviors. It has been postulated that binging and vomiting serve to block awareness of the negative emotions and cognitions (Heatherton \& Baumeister, 1991; Lacey, 1986; Root \& Fallon, 1989) that are common sequelae of sexual abuse. Further research is needed to investigate whether Waller's (1992) finding is reliable, and to assess whether this relationship with bulimic behaviors holds only for categorical severity of abuse, or whether a dimensional relationship (i.e., a positive correlation between two continuous variables) exists between these phenomena.

More recently, investigators have begun to consider the role of other types of child abuse in the etiology of eating disorders, including child physical abuse (CPA), child emotional abuse (CEA) and neglect. A preliminary controlled study by Rorty et al. (1994) examined rates of childhood sexual, physical, and psychological abuse in women with a history of bulimia and in nonclinical controls. This study found significantly higher rates of physical, psychological, and multiple abuses in the bulimic group, but the prevalence of childhood sexual abuse (CSA) was not significantly different. Consequently, these authors argued that researchers need to consider the full range of abusive experiences, rather than concentrating solely on sexual abuse. In support of this conclusion, studies involving non- 
clinical samples have found that a more refined relationship exists between the severity of other forms of abuse and severity of eating pathology (Kent, Waller, \& Dagnan, 1999; Reto, Dalenberg, \& Coe, 1993). Reto et al. (1993) found that severity of CPA predicted severity of bulimic pathology in a female student sample. Kent et al. (1999) investigated the relationship between the severity of four forms of child abuse (CEA, neglect, CPA, CSA) and eating pathology in a nonclinical sample. These authors found that with the exception of CSA, all forms of abuse were correlated with eating pathology. A multiple regression analysis revealed that CEA was the most parsimonious predictor of pathology. There is a need for further studies to examine whether there is a dimensional relationship between different forms of child abuse and eating pathology within clinical samples.

Research has also begun to focus on elucidating factors that explain the relationship between child abuse and eating disorders. In order to build a comprehensive model of the link between these two phenomena, which can guide formulation and treatment of individual cases, it is necessary to investigate the psychological variables that mediate this relationship. Dissociation has received a lot of research attention. Studies have reported that the presence of physical abuse (e.g., McCallum, Lock, Kulla, Rorty, \& Wetzel, 1992; McCarthy, Goff, Baer, Cioffi, \& Herzog, 1994) and sexual abuse (e.g., Herzog, Stoley, Carmody, Robbins, \& van der Kolk, 1993) are associated with higher levels of dissociation in eating-disordered women. Dissociation has been found to act as a mediator in the relationship between the presence of sexual abuse and severity of binging in women with bulimic disorders (Everill, Waller, \& Macdonald, 1995a). In addition, there is some evidence from nonclinical samples that dissociation may mediate between severity of other forms of child abuse (i.e., CEA and CPA) and eating pathology (Kent et al., 1999; Reto et al., 1993). However, researchers have not yet investigated whether there is a dimensional relationship between childhood abuse and dissociation in a clinical sample.

In the same vein, researchers have considered the role of cognitive content in the relationship between sexual abuse and bulimic disorders. Pitts and Waller (1993) report that self-denigratory beliefs (related to the abuse) partially mediated the relationship between sexual abuse and frequency of vomiting in a group of women with eating disorders. More recently, researchers have begun to consider the content of underlying schemas (also known as core beliefs) in women with bulimia who have been sexually abused. Waller et al. (in press) used Young's Schema Questionnaire (YSQ; Young, 1994) to assess core beliefs in bulimic women with and without a history of sexual abuse. In this study, abused bulimics had significantly higher scores on 9 out of 16 schemas measured by the YSQ scales, and had higher levels of binging and vomiting. Analysis of covariance revealed that these 9 schemas accounted for the differences in levels of symptomatology between the two groups, suggesting that the beliefs act as mediators in the relationship between abuse and severity of bulimic behaviors. In addition, within the abused group, beliefs about the need for emotional inhibition correlated with frequency of binging, and beliefs about inherent defectiveness and fear of abandonment correlated with frequency of vomiting. This study showed a dimensional relationship between core beliefs and bulimic behaviors in abused bulimics. The present study will investigate whether there is a dimensional relationship between different forms of reported childhood abuse and core beliefs in bulimics.

Given the hypothesized function of bulimic behaviors (i.e., reduction of awareness of negative cognitions and emotions consequent on abuse), it is likely that core beliefs shown to have 
a dimensional relationship with bulimic behaviors (i.e., Defectiveness/shame, Emotional inhibition, Abandonment) in abused bulimics (Waller et al., in press) will also have a dimensional relationship with abuse. In addition, Young's (1994) descriptions of the origins of different schemas suggests that beliefs about Mistrust/abuse and Emotional deprivation are also likely to be dimensionally associated with abuse.

The present study of a group of women with bulimic disorders has two aims. First, it will examine the relationship between different forms of reported childhood abuse (CEA, Neglect, CSA, CPA) and bulimic pathology. It is hypothesized that there will be a dimensional relationship between reported abuse and bulimic attitudes and behaviors. Second, this study will investigate the relationship of child abuse with dissociation and core beliefs. It is hypothesized that there will be a dimensional relationship between reported abuse and dissociation. In addition, on the basis of previous research and clinical descriptions (Waller et al., in press; Young, 1994), it is hypothesized that there will be a dimensional relationship between reported abuse and core beliefs (in particular: Defectiveness/shame, Emotional deprivation, Abandonment, Mistrust/abuse, and Emotional inhibition).

\section{Method}

\section{Design}

This study employed a client series correlational design. It tested whether severity of reported abuse in a group of bulimics was associated with measures of dissociation, cognitive content, and bulimic pathology.

\section{Participants}

The participants were 23 bulimic women who met DSM-IV criteria (American Psychiatric Association, 1994) for bulimia nervosa $(N=15)$, binge eating disorder $(N=3)$ or anorexia of the binge/purge subtype $(N=5)$. Their mean age was 29.4 years $(S D=9.4)$, and their mean body mass index $\left(\mathrm{BMI}=\right.$ weight $\left.[\mathrm{kg}] / \mathrm{height}[\mathrm{m}]^{2}\right)$ was $24.7(S D=7.3)$. Restrictive anorexics were excluded from this study, since the hypotheses are concerned with bulimic attitudes and behaviors. No male clients were referred over the course of the study. The participants were recruited by Clinical Psychologists working for two eating disorder services in the United Kingdom. A further four bulimic patients (three diagnosed with bulimia nervosa, and one with binge eating disorder) were approached, but decided not to participate. A further seven patients (four diagnosed with bulimia nervosa, and three with anorexia nervosa of the binge/purge subtype) initially agreed to participate, but then failed to complete the measures adequately. There were no differences in age or mean BMI between those who participated and those who declined or who failed to complete the measures $(t<.50$ in each case).

\section{Measures}

Each participant was asked to complete four questionnaires, assessing abusive experiences, dissociation, core beliefs, and bulimic pathology. These questionnaires were self-administered, 
and took approximately 50 minutes to complete. In addition, participants were asked to keep diary records of binging and vomiting over a period of 2 weeks, to allow the frequency of bulimic behaviors to be assessed.

The Child Abuse and Trauma Scale (CATS; Sanders \& Becker-Lausen, 1995). The CATS is a 38-item questionnaire, which measures subjective reports of childhood emotional abuse, neglect, physical abuse, and sexual abuse. Participants are required to indicate on a $0-4$ scale (0: never; 4: always) how frequently each of a range of abusive experiences happened to them during their childhood and adolescence. Higher scores reflect more frequent abusive experiences, and are taken to give an index of severity. The validity and reliability of the CATS has been documented (Sanders \& Becker-Lausen, 1995). The original version of this scale (Sanders \& Becker-Lausen, 1995) yields a total score and individual scores on three subscales: negative home atmosphere/neglect (Neglect: 14 items); child physical abuse/punishment (CPA: 6 items); and child sexual abuse (CSA: 6 items). On each subscale, the participant's score is the mean of the items in that scale. Subsequently, Kent and Waller (1998) have created a further emotional abuse subscale (CEA: 7 items), made up of six CATS items not used in other subscales and one item that is included in the Neglect subscale. The items in this subscale are reported to have high face validity for the construct of CEA, and acceptable levels of internal consistency and concurrent validity (Kent \& Waller, 1998). For the purposes of the present study, all four subscales will be used, in order to allow assessment of four types of reported child abuse.

Definitions of abuse. In the present study, definitions of abuse were based on those operationalized in the CATS scale. CEA was defined as parental behaviors perceived as ridiculing, insulting, unpredictable, or blaming. Neglect was defined as experiences of feeling unwanted, unsupported or lonely, or of being left to take care of oneself. CPA was defined broadly as experiences of being severely punished, hit or beaten unexpectedly, and more generally of having to follow strict rules at home. Finally, CSA was defined as sexual experiences with an adult before age 14, sexual experiences with a parent, or other traumatic sexual experiences.

The Young Schema Questionnaire (YSQ; Young, 1994). The YSQ is a 75-item self-report questionnaire, which assesses "early maladaptive schemas." These are unconditional beliefs about oneself and one's environment, developed as a result of dysfunctional childhood experiences. Those beliefs become maladaptive over time and with changed circumstances. Such schemas are argued to be self-perpetuating, in that individuals are likely to distort new information in order to maintain the validity of the schema (Young, 1994). The YSQ was originally designed for use with individuals with personality disorders, and consisted of 205 items (Young, 1994), which measure 16 schemas (Schmidt, Joiner, Young, \& Telch, 1995). The shortened version has been shown to have equivalent psychometric properties and greater convenience in clinical settings than the 205-item version (Waller, Ohanian, \& Meyer, 2001), and so it was used in this study.

This version of the YSQ measures the following 15 schemas (five items each):

- Emotional deprivation (the belief that one's emotional needs will not be met by others); 
- Abandonment (the belief that one will imminently lose significant others and be emotionally isolated);

- Mistrust/abuse (the belief that others will be manipulative or abusive);

- Social isolation (the belief that one is different from others, and isolated from the world);

- Defectiveness/shame (the belief that one is inwardly defective, or fundamentally unlovable);

- Failure to achieve (the belief that one is inadequate, has failed or will inevitable fail);

- Dependence/incompetence (the belief that one cannot cope without the guidance or support of others);

- Vulnerability to harm or illness (the belief that one is unable to control the threat of disaster);

- Enmeshment (excessive involvement with significant others, and the belief that one will be unable to cope without them);

- Subjugation (the belief that one's own needs and feelings are not as important as those of others);

- Self-sacrifice (the belief that one should meet the needs of others, rather than one's own);

- Emotional inhibition (the belief that emotional expression is undesirable or unacceptable, and may result in aversive consequences);

- Unrelenting standards (the belief that one should strive to meet very high levels of achievement);

- Entitlement (the belief that one can act without regard for others); and

- Insufficient self-control (the belief that one cannot or need not control emotions or impulses).

Participants respond by rating themselves for each item on a 6-point scale $(1=$ completely untrue of me; $6=$ describes me perfectly), where a higher score indicates a more maladaptive schema. In the present study, mean scores were calculated for each subscale (as suggested by Schmidt et al., 1995), in order to allow for comparison across scales.

The Dissociative Experiences Scale II (DES II; Carlson \& Putnam, 1993). This is a 28-item self-report questionnaire, designed to assess the frequency of dissociative experiences in adult clinical populations. It assesses experiences of amnesia, depersonalization, derealization, absorptionl, and imaginative involvement, not occurring under the influence of drugs or alcohol. Participants are asked to rate how often they have experienced each of the dissociative phenomena described (on a visual analogue scale of 0-100\%), with higher scores reflecting greater pathology. The score for the scale is an average of the 28 individual items. The DES II has well established validity and reliability (Bernstein \& Putnam, 1986; Frischolz et al., 1990, 1991). Normative data are also available for individuals with eating disorders (Demitrack, Putnam, Brewerton, Brandt, \& Gold, 1990; Everill, Waller, \& Macdonald, 1995b; Goldner, Cockhill, Bakan, \& Birmingham, 1991).

The Bulimic Investigatory Test, Edinburgh (BITE; Henderson \& Freeman, 1987). The BITE is a 33-item self-report measure, designed to measure the symptoms of bulimia or binge-eating. It consists of two subscales - the Symptom scale (which measures the number of cognitive and 
behavioral symptoms present); and the Severity scale (which measures the frequency of binging and purging behaviors). The scale has well established validity and reliability (Henderson \& Freeman, 1987).

\section{Procedure}

Following ethical approval, Clinical Psychologists working for the eating disorder services were provided with guidelines for recruiting participants. Each participant was recruited during an assessment phase prior to treatment, in order to avoid the confounding effect of therapeutic intervention on symptoms of dissociation and bulimia. Participants were provided with an information sheet, which explained that the purpose of the study was to investigate experiences and beliefs of individuals with bulimic symptoms, and which addressed issues of confidentiality, anonymity, and freedom to withdraw from the study. Individuals who were willing to participate were asked to sign a consent form, which also asked them whether they were happy for the results of the questionnaires to be shared with their individual therapists. Participants were then asked to complete the four questionnaires. Where necessary they were provided with therapeutic support in relation to issues raised by the questionnaires.

\section{Data analysis}

The data were normally distributed, so parametric analyses were used. Pearson's correlation coefficient was used to determine the correlations between: child abuse and bulimic pathology; child abuse and dissociation; child abuse and core beliefs. Given that the direction of the relationships between variables had been predicted (see hypotheses), one-tailed tests were used. Due to the number of correlations involved in the analysis involving the YSQ, an alpha level of .025 was adopted in that part of the results, in order to reduce the risk of Type I errors.

\section{Results}

\section{Group characteristics}

The mean overall CATS score was $1.19(S D=.82)$. The mean scores on each individual subscale were: emotional abuse $=1.39(S D=.94)$; negative home atmosphere/neglect $=$ $1.40(S D=.98)$; physical abuse/punishment $=1.43(S D=.83)$; and sexual abuse $=.44$ $(S D=.63)$. As would be expected, these scores are higher than those reported for nonclinical samples (Kent \& Waller, 1998; Sanders \& Becker-Lausen, 1995). These scores are also less than half those reported for the three original subscales for a sample of adults with DSM-III-R (American Psychiatric Association, 1987) Multiple Personality Disorder (Sanders \& Becker-Lausen, 1995), and slightly lower than those reported for an inpatient adolescent sample (Sanders \& Giolas, 1991).

The women's mean DES score was $16.4(S D=13.9)$. This is very similar to scores previously reported for eating disorder samples (e.g., Demitrack et al., 1990; Everill et al., 1995b; Goldner et al., 1991). The mean scores on the BITE were: Symptoms $=22.4$ 
Table 1

Mean scores on the YSQ subscales

\begin{tabular}{ll}
\hline YSQ subscale & Mean $(S D)$ \\
\hline Emotional deprivation & $3.18(1.67)$ \\
Abandonment & $3.61(1.36)$ \\
Mistrust/abuse & $3.49(1.49)$ \\
Social isolation & $3.36(1.38)$ \\
Defectiveness/shame & $3.50(1.50)$ \\
Failure to achieve & $3.43(1.55)$ \\
Functional dependence & $2.86(1.13)$ \\
Vulnerability to harm & $2.63(1.21)$ \\
Enmeshment & $2.00(1.10)$ \\
Subjugation & $3.42(1.38)$ \\
Self-sacrifice & $3.93(1.29)$ \\
Emotional inhibition & $3.26(1.32)$ \\
Unrelenting standards & $3.70(1.39)$ \\
Entitlement & $2.43(1.01)$ \\
Insufficient self-control & $4.03(1.18)$ \\
\hline
\end{tabular}

$(S D=4.08)$; and Severity $=11.2(S D=5.05)$. As expected, these fall within the clinical range (Henderson \& Freeman, 1987). Mean frequencies of binging and vomiting per week (diary measures) were $3.70(S D=2.27)$ and $3.45(S D=2.76)$. Again, these are very similar to the levels reported by other studies (e.g., Everill et al., 1995b). The mean scores on the YSQ subscales are shown in Table 1. A similar range of scores has previously been found in a bulimic sample (Waller, Ohanian, Meyer, \& Osman, 2000).

Is severity of abuse related to severity of bulimic pathology? Table 2 shows the correlations (Pearson's $r$, one-tailed) between severity of reported abuse and severity of bulimic pathology. No significant relationships were found with any of the dimensional CATS scales, even at a .1 level of significance. This result conflicts with the finding by Waller (1992) that more severe sexual abuse (measured categorically) was associated with a higher rate of bulimic behaviors in a bulimic sample. Despite this lack of significance, it is worthy of note that the correlations of trauma variables with bulimic attitudes and vomiting behaviors were in the expected positive direction (i.e., more severe trauma is associated with more pathology), while the correlations with the severity of bulimia and of binging were broadly negative (i.e., more severe trauma is associated with less pathology). While these numbers are insufficient to reach firm conclusions,

Table 2

Correlations (Pearson's $r$, one-tailed) between severity of abuse and bulimic pathology

\begin{tabular}{lccccr}
\hline & \multicolumn{6}{l}{ Child Abuse and Trauma Scale } & & \\
\cline { 2 - 6 } & Emotional abuse & Neglect & Physical abuse & Sexual abuse & Total \\
\hline BITE—symptoms & .14 & .26 & .09 & .10 & .22 \\
BITE—severity & -.07 & -.18 & -.06 & -.25 & -.13 \\
Frequency of binging & -.36 & -.23 & -.02 & .01 & -.19 \\
Frequency of vomiting & .18 & .22 & .29 & .13 & .20 \\
\hline
\end{tabular}


they indicate that future research should consider the possibility that trauma is more strongly related to purging than binging behaviors.

A post hoc analysis was carried out to investigate whether the simple presence or absence of sexual abuse was related to the severity of bulimic pathology. This was only carried out in the case of sexual abuse because nearly all participants reported some experience of emotional abuse $(N=22)$ or neglect $(N=21)$, and all participants reported experiencing some physical abuse/punishment. Conversely, only 10 out of the 23 participants $(43.5 \%)$ reported some experience of sexual abuse. This prevalence rate is similar to those reported by other studies (e.g., Everill et al., 1995a; Waller, 1991). However, independent samples $t$ tests showed that there were no significant relationships between the presence of sexual abuse and bulimic pathology (BITE symptoms $[t=.14]$; BITE severity $[t=1.22]$; binge frequency $[t=.71]$; vomit frequency $[t=.06])$.

Is severity of abuse related to severity of dissociation? Pearson's correlation coefficient (onetailed) was used to determine whether severity of reported abuse was related to severity of dissociation. A positive correlation was found between overall severity of abuse and dissociation $(r=.40 ; p<.05)$. This was a product of individual correlations between dissociation levels and scores on two subscales: Neglect $(r=.46 ; p<.25)$ and CSA $(r=.41 ; p<.05)$. No significant correlation was found with the subscales measuring CEA $(r=.31)$ or CPA $(r=.29)$.

Is severity of abuse related to core beliefs? Table 3 shows the correlations (Pearson's $r$, one-tailed) between severity of different forms of abuse and YSQ scores. Severity of abuse

Table 3

Correlations (Pearson's $r$, one tailed) between severity of abuse and core beliefs

\begin{tabular}{lccccc}
\hline & \multicolumn{2}{l}{ Child Abuse and Trauma Scale } & & & \\
\cline { 2 - 6 } & Emotional abuse & Neglect & Physical abuse & Sexual abuse & Total \\
\hline Emotional deprivation & .34 & .41 & $.44^{*}$ & $.43^{*}$ & $.44^{*}$ \\
Abandonment & .15 & .08 & -.09 & .21 & .07 \\
Mistrust/abuse & $.42^{*}$ & $.43^{*}$ & .17 & $.45^{*}$ & .41 \\
Social isolation & .33 & .36 & .16 & .41 & .36 \\
Defectiveness/shame & $.44^{*}$ & .41 & .23 & .34 & .40 \\
Failure to achieve & .26 & .25 & -.07 & .28 & .22 \\
Functional dependence & .13 & .10 & -.01 & .26 & .09 \\
Vulnerability to harm & $.57^{*}$ & $.55^{*}$ & .39 & .17 & $.56^{* *}$ \\
Enmeshment & .07 & .18 & .07 & $.48^{*}$ & .13 \\
Subjugation & .33 & .28 & .11 & .22 & .30 \\
Self-sacrifice & -.39 & -.25 & -.23 & $.42^{*}$ & -.28 \\
Emotional inhibition & $.44^{*}$ & $.44^{*}$ & .15 & .21 & .41 \\
Unrelenting standards &. .05 & .01 & -.18 &. .17 & -.09 \\
Entitlement & .16 & .22 & .05 & .07 & .08 \\
Insufficient self-control & .09 & .16 & & .12
\end{tabular}

${ }^{*} p<.025$.

** $p<.005$. 
was associated with six core beliefs: Defectiveness/shame; Emotional deprivation; Emotional inhibition; Mistrust/abuse; Subjugation; and Vulnerability to harm. Interestingly, five out of these six core beliefs (with the exception of Subjugation) constitute a subset of the nine core beliefs found to differentiate sexually abused bulimics from nonabused bulimics in a study by Waller et al. (in press). Four of these core beliefs (with the exception of Subjugation and Defectiveness/shame) were positively correlated with the severity of two or more individual forms of abuse.

Individual forms of abuse showed different correlational profiles. CEA correlated with beliefs about Defectiveness/shame, Emotional inhibition, Mistrust/abuse, and Vulnerability to harm. Neglect correlated with beliefs about Emotional inhibition, Mistrust/abuse, and Vulnerability to harm. CPA was correlated only with a belief about Emotional deprivation. Finally, CSA correlated with beliefs about Emotional deprivation, Emotional inhibition, Mistrust/abuse, and Subjugation.

\section{Discussion}

The aim of this study of bulimic women was to investigate whether higher levels of reported abuse were associated with more severe bulimic pathology, with more severe dissociation, and with severity of a subset of core beliefs. Three findings emerged. First, contrary to expectations, severity of reported abuse was not associated with more severe bulimic pathology. Second, as predicted, severity of neglect and sexual abuse were associated with severity of dissociation. Third, severity of abuse was associated with more pathological scores on 6 out of 15 core beliefs. Core beliefs related to abusive experiences (Mistrust/abuse, Vulnerability to harm, Emotional deprivation) and core beliefs about strategies for coping (Emotional inhibition, Subjugation) showed different patterns of association with abuse forms. Emotional abuse and Neglect were associated with core beliefs about Mistrust/abuse, Vulnerability to harm, and Emotional inhibition. Sexual abuse was associated with core beliefs about Mistrust/abuse, Emotional deprivation, Emotional inhibition and Subjugation, and physical abuse was associated with a core belief about Emotional deprivation. In addition, emotional abuse was associated with a core belief about low self-worth (Defectiveness/shame). These associations will be returned to below.

The present findings suggest that there is not a dimensional relationship between the severity of different forms of child abuse and severity of bulimic pathology. In the case of reported sexual abuse, this finding contrasts with the results of a study by Waller (1992), which also used diary records to assess frequency of binging and vomiting. This discrepancy might be explained by the fact that the present study used a different measure of severity of sexual abuse. It may be that categorical measures of abuse severity (such as presence/absence of force or intrafamilial/nonfamilial abuse - as used by Waller, 1992) are relevant to the severity of bulimic behaviors, whereas truly dimensional measures of severity (as used in the present study) are not. Some support for this proposal is provided by the study by Kent et al. (1999), which also failed to find a correlation between severity of sexual abuse (measured by the CATS) and eating pathology in a nonclinical sample. In relation to other forms of abuse, the results of the present study contrast with studies involving nonclinical samples, which have 
found a dimensional relationship between eating pathology and physical abuse (Reto et al., 1993) and emotional abuse (Kent et al., 1999). However, it may be that no truly dimensional relationship exists between other forms of child abuse and bulimic pathology in a clinical sample. The other possibility is that the small sample used in the present study did not give the study sufficient power to find these dimensional relationships, and that a larger number of participants might have confirmed the suggested specificity of links to purging behaviors. A power analysis based on the present findings indicates that a sample size of 88 would be necessary to ensure $90 \%$ power with an alpha level of 5\%, and this gives a good indication of the sample sizes that should be sought in future research of this kind.

A relationship was found between dissociation and the severity of sexual abuse and neglect. With regard to sexual abuse, this is in line with previous studies involving eating disorder samples (e.g., Everill et al., 1995a; Herzog et al., 1993). However, the present study extends these findings, showing a dimensional relationship between CSA and dissociation. There was also a dimensional relationship between severity of neglect and severity of dissociation, which concurs with existing studies (Sanders \& Giolas, 1991; van der Kolk, Perry, \& Herman, 1991) of other psychiatric samples. Gauthier, Stollak, Messe, and Aronoff (1996) have recently argued that neglect is likely to be associated with greater pathology than more active abuse because it is the equivalent of total psychological abandonment. The present finding supports that proposal, indicating that neglect is the form of abuse most strongly associated with dissociation in bulimic women.

Severity of reported abuse was associated with more pathological scores on six core beliefs. As highlighted previously, this result partially replicates the findings of Waller et al. (in press). Different patterns of association emerged between forms of abuse and core beliefs. The most common type of core beliefs were those relating to traumatic experiences per se. Mistrust/abuse (i.e., the belief that others will be manipulative or abusive) was associated with emotional abuse, neglect and sexual abuse, but not physical abuse. This might be because this core belief tends to be associated with the perception of having been treated unfairly (Young, 1994), and physical abuse may be less likely to be perceived as unfair because it is often contingent on certain behaviors, whereas other forms of abuse are not. Vulnerability to harm (i.e., the belief that one is unable to control the threat of disaster) was associated with emotional abuse and neglect, but not with physical or sexual abuse. This might be explained by the fact that CEA and neglect are more insidious forms of abuse, involve more anxiety and uncertainty, and are less easy to escape from. They are therefore more likely to be associated with perceptions of personal vulnerability. Lastly, Emotional deprivation (i.e., the belief that one's emotional needs will not be met by others) was associated with physical and sexual abuse, but not emotional abuse or neglect. This pattern is less easy to explain. Interestingly, the correlation between neglect and Emotional deprivation just failed to reach significance, and it is possible that a stronger association might have been found with a larger sample of participants.

Core beliefs about strategies for coping and self-worth were also associated with child abuse. Emotional inhibition (i.e., the belief that emotional expression is undesirable or unacceptable, and may result in aversive consequences) was associated with emotional abuse, neglect and sexual abuse, but not physical abuse. This pattern indicates that Emotional inhibition is also more related to noncontingent forms of abuse. This suggests that individuals who are physically 
abused are less likely to learn that emotional expression is unacceptable or dangerous. In other words, it may be seen as more acceptable to be upset about physical abuse/punishment than about more insidious (i.e., CEA, neglect) or secretive (i.e., CSA) forms of abuse. In addition, Subjugation (i.e., the belief that others' needs are more important than one's own) was associated with sexual abuse. Young (1994) proposes that this belief is likely to develop if an individual is controlled during childhood, and this association may be explained by the fact that sexual abuse involves the victim's feelings and needs being ignored and overridden. Finally, Defectiveness/shame (i.e., the belief that one is inwardly defective or fundamentally unlovable) was associated only with emotional abuse. This finding is in line with Young's (1994) proposal that individuals are likely to develop this belief if their parents are critical and make them feel unworthy. It suggests that the insidiousness of CEA may mean that individuals are more likely to attribute such experiences to their own lack of self-worth, whereas other forms of abuse may be more easily attributed externally. Interestingly, the association between neglect and Defectiveness/shame just failed to reach significance, which indicates that the same may be true for this form of abuse.

The present findings need to be interpreted with caution for a number of reasons. In particular, the sample of participants was small and was heterogeneous with regard to eating disorder diagnoses. In addition, the data were elicited using self-report measures-a method that is arguably less reliable than clinical interview. However, it is also possible that anonymity may have enabled participants to be relatively honest about their feelings and experiences. Consequently, while this study suggests some interesting patterns of association, it serves as more of a pilot study, which has highlighted some useful areas for further research attention. It would be valuable to extend this study to larger, more homogeneous samples, and to include psychiatric and nonclinical comparison groups. Such a research design could determine if different abusive experiences and core beliefs need to be addressed therapeutically in different types of disorder. A larger sample size would also allow a mediator model to be tested, to determine whether dissociation and core beliefs mediate any links between different forms of abuse and bulimic pathology. Such a model could be extended to include consideration of other impulsive behaviors (such as self-harm and substance abuse), which are argued to serve a similar function to bulimic behaviors (e.g., Lacey, 1993; Lacey \& Evans, 1986). Finally, it would also be useful if future studies were to compare the utility of categorical and dimensional measures of abuse severity.

While acknowledging the above limitations, this research study suggests some interesting preliminary clinical implications for working with bulimics. Specifically, the results suggest that, where addressing childhood trauma is a clinical target in work with this population, schema-focused therapies (e.g., Padesky, 1994; Young, 1994) are potentially useful. However, further research is needed to determine which forms of trauma and particular core beliefs are most relevant to bulimic disorders, and how this clinical picture differs across bulimic subgroups.

\section{Acknowledgments}

The authors would like to thank Lorraine Bell and Maggie Bellhouse for their assistance in obtaining data. 


\section{References}

Abramson, E. E., \& Lucido, G. M. (1991). Childhood sexual experience and bulimia. Addictive Behaviors, 16, 529-532.

American Psychiatric Association. (1987). Diagnostic and statistical manual of mental disorders (3rd ed., revised). Washington, DC: American Psychiatric Association.

American Psychiatric Association. (1994). Diagnostic and statistical manual of mental disorders (4th ed.). Washington, DC: American Psychiatric Association.

Bernstein, E. M., \& Putnam, F. W. (1986). Development, reliability, and validity of a dissociation scale. Journal of Nervous and Mental Disease, 174, 727-735.

Carlson, E. B., \& Putnam, M. D. (1993). An update on the Dissociative Experiences Scale. Dissociation, 6, 16-25.

Connors, M. E., \& Morse, W. (1993). Sexual abuse and eating disorders: A review. International Journal of Eating Disorders, 13, 1-11.

Demitrack, M. A., Putnam, F. W., Brewerton, T. D., Brandt, H. A., \& Gold, P. W. (1990). Relation of clinical variables to dissociative phenomena in eating disorders. American Journal of Psychiatry, 147, 1184-1188.

Everill, J., Waller, G., \& Macdonald, W. (1995a). Reported sexual abuse and bulimic symptoms: The mediating role of dissociation. Dissociation, 8, 155-159.

Everill, J., Waller, G., \& Macdonald, W. (1995b). Dissociation in bulimic and non-eating-disordered women. International Journal of Eating Disorders, 17, 127-134.

Fahy, T. A., \& Eisler, I. (1993). Impulsivity and eating disorders. British Journal of Psychiatry, 162, 193-197.

Folsom, V., Krahn, D., Nairn, K., Gold, L., Demitrack, M. A., \& Silk, K. R. (1993). The impact of sexual and physical abuse on eating disordered and psychiatric symptoms: A comparison of eating disordered and psychiatric inpatients. International Journal of Eating Disorders, 13, 249-257.

Frischolz, E. J., Braun, B. G., Sachs, R. G., Hopkins, L., Schaeffer, D. M., Lewis, J., Leavitt, F., Pasquotto, M. A., \& Schwartz, D. R. (1990). The Dissociative Experiences Scale: Further replication and validation. Dissociation, 3, 151-153.

Frischolz, E. J., Braun, B. G., Sachs, R. G., Schwartz, D. R., Lewis, J., Schaeffer, D., Westergaard, C., \& Pasquotto, J. (1991). Construct validity of the Dissociative Experiences Scale (DES): 1. The relation between the DES and other self-report measures of dissociation. Dissociation, 4, 185-188.

Fullerton, D. T., Wonderlich, S. A., \& Gosnell, B. A. (1995). Clinical characteristics of eating disorder patients who report sexual or physical abuse. International Journal of Eating Disorders, 17, 243-249.

Gauthier, L., Stollak, G., Messe, L., \& Aronoff, J. (1996). Recall of childhood neglect and physical abuse as differential predictors of current psychological functioning. Child Abuse \& Neglect, 20, 549-559.

Garfinkel, P. E., Lin, E., Goering, P., Spegg, C., Goldbloom, D. S., Kennedy, S., Kaplan, A. S., \& Woodside, D. B. (1995). Bulimia nervosa in a Canadian community sample: Prevalence and comparison of subgroups. American Journal of Psychiatry, 152, 1052-1058.

Goldner, E. M., Cockhill, L. A., Bakan, R., \& Birmingham, C. L. (1991). Dissociative experiences in eating disorders. American Journal of Psychiatry, 148, 1274-1275.

Hall, R. C. W., Tice, L., Beresford, T. P., Wooley, B., \& Hall, A. K. (1989). Sexual abuse in patients with anorexia nervosa and bulimia. Psychosomatics, 30, 73-79.

Hastings, T., \& Kern, J. M. (1994). Relationships between bulimia, childhood sexual abuse and family environment. International Journal of Eating Disorders, 15, 103-111.

Heatherton, T. F., \& Baumeister, R. F. (1991). Binge eating as an escape from self-awareness. Psychological Bulletin, 110, 86-108.

Henderson, M., \& Freeman, C. P. L. (1987). A self-rating scale for bulimia: The "BITE". British Journal of Psychiatry, 150, 18-24.

Herzog, D. B., Stoley, J. E., Carmody, S., Robbins, W. M., \& van der Kolk, B. A. (1993). Childhood sexual abuse in anorexia nervosa and bulimia nervosa: A pilot study. Journal of the American Academy of Child and Adolescent Psychiatry, 32, 962-966.

Kent, A., \& Waller, G. (1998). The impact of childhood emotional abuse: An extension of the Child Abuse and Trauma Scale. Child Abuse \& Neglect, 22, 393-399. 
Kent, A., Waller, G., \& Dagnan, D. (1999). A greater role of emotional than physical or sexual abuse in predicting disordered eating attitudes: The role of mediating variables. International Journal of Eating Disorders, 25, $159-167$.

Lacey, J. H. (1986). Pathogenesis. In L. J. Downey \& J. C. Malkin (Eds.), Current approaches: Bulimia nervosa. Southampton, UK: Duphar.

Lacey, J. H. (1993). Self-damaging and addictive behavior in bulimia nervosa: A catchment area study. British Journal of Psychiatry, 163, 190-194.

Lacey, J. H., \& Evans, C. D. H. (1986). The impulsivist: A multi-impulsive personality disorder. British Journal of Addiction, 81, 641-649.

McCallum, K. E., Lock, J., Kulla, M., Rorty, M., \& Wetzel, R. D. (1992). Dissociative symptoms and disorders in patients with eating disorders. Dissociation, 5, 227-235.

McCarthy, M. K., Goff, D. C., Baer, L., Cioffi, J., \& Herzog, D. B. (1994). Dissociation, childhood trauma, and response to fluoxetine in bulimia patients. International Journal of Eating Disorders, 15, 219-226.

Oppenheimer, R., Howells, K., Palmer, R. L., \& Chaloner, D. A. (1985). Adverse sexual experience in childhood and clinical eating disorders: a preliminary description. Journal of Psychiatric Research, 19, 357-361.

Padesky, C. A. (1994). Schema change processes in cognitive therapy. Clinical Psychology and Psychotherapy, 1 , 267-278.

Pitts, C., \& Waller, G. (1993). Self-denigratory beliefs following sexual abuse: association with the symptomatology of bulimic disorders. International Journal of Eating Disorders, 13, 407-410.

Reto, C. S., Dalenberg, C. J., \& Coe, M. T. (1993). Dissociation and physical abuse as predictors of bulimic symptomatology and impulse dysregulation. Eating Disorders: The Journal of Treatment and Prevention, 1 , 226-239.

Root, M. P. P., \& Fallon, P. (1988). The incidence of victimization in a bulimic sample. Journal of Interpersonal Violence, 3, 161-173.

Root, M. P. P., \& Fallon, P. (1989). Treating the victimized bulimic. Journal of Interpersonal Violence, 4, 90-100.

Rorty, M., Yager, J., \& Rossotto, E. (1994). Childhood sexual, physical, and psychological abuse in bulimia nervosa. American Journal of Psychiatry, 151, 1122-1126.

Sanders, B., \& Becker-Lausen, E. (1995). The measurement of psychological maltreatment: Early data on the Child Abuse and Trauma Scale. Child Abuse \& Neglect, 19, 315-323.

Sanders, S., \& Giolas, M. H. (1991). Dissociation and childhood trauma in psychologically disturbed adolescents. American Journal of Psychiatry, 148, 50-54.

Schmidt, N. B., Joiner, T. E., Young, J. E., \& Telch, M. J. (1995). The Schema Questionnaire: Investigation of psychometric properties and hierarchical structure of a measure of maladaptive schemas. Cognitive Therapy and Research, 19, 295-321.

Slade, P. D. (1982). Towards a functional analysis of anorexia nervosa and bulimia nervosa. British Journal of Clinical Psychology, 21, 167-179.

Steiger, H., \& Zanko, M. (1990). Sexual traumata among eating disordered, psychiatric, and normal female groups. Journal of Interpersonal Violence, 5, 74-86.

Sullivan, P. F., Bulik, C. M., Carter, F. A., \& Joyce, P. R. (1995). The significance of a history of childhood sexual abuse in bulimia nervosa. British Journal of Psychiatry, 167, 679-682.

van der Kolk, B. A., Perry, C., \& Herman, J. L. (1991). Childhood origins of self-destructive behavior. American Journal of Psychiatry, 148, 1665-1671.

Vize, C. M., \& Cooper, P. J. (1995). Sexual abuse in patients with eating disorder, patients with depression, and normal controls: A comparative study. British Journal of Psychiatry, 167, 80-85.

Waller, G. (1991). Sexual abuse as a factor in the eating disorders. British Journal of Psychiatry, 159, 664-671.

Waller, G. (1992). Sexual abuse and the severity of bulimic symptoms. British Journal of Psychiatry, 161, 90-99.

Waller, G., Halek, G., \& Crisp, A. H. (1993). Sexual abuse as a factor in anorexia nervosa. Evidence from two separate case series. Journal of Psychosomatic Research, 17, 873-879.

Waller, G., Meyer, C., Ohanian, V., Elliott, P., Dickson, C., \& Sellings, J. (in press). The psychopathology of bulimic women who report childhood sexual abuse: The mediating role of core beliefs. Journal of Nervous and Mental Disease. 
Waller, G., Ohanian, V., \& Meyer, C. (2001). Psychometric properties of the long and short versions of the Young Schema Questionnaire: Core beliefs among bulimic and comparison women. Cognitive Therapy and Research, $25,137-147$.

Waller, G., Ohanian, V., Meyer, C., \& Osman, S. (2000). Cognitive content among bulimic women: The role of core beliefs. International Journal of Eating Disorders, 28, 235-241.

Welch, S. L., \& Fairburn, C. G. (1994). Sexual abuse and bulimia nervosa: Three integrated case control comparisons. American Journal of Psychiatry, 151, 402-407.

Young, J. E. (1994). Cognitive therapy for personality disorders: A schema-focused approach (2nd ed.). Sarasota: Professional Resource Press.

\section{Résumé}

Objectif: Cette étude portant sur des femmes boulimiques a examiné le lien entre la sévérité de quatre types de mauvais traitements signalés (émotifs, physiques, sexuels et négligence) et la pathologie boulimique. De plus, on a étudié le lien entre les mauvais traitements d'une part et les croyances fondamentales et la dissociation d'autre part.

Méthode: Un échantillon de 23 femmes boulimiques ont complété des tests standardisés mesurant les mauvais traitements, la dissociation, les croyances fondamentales et les symptômes boulimiques. Elles ont aussi noté leurs comportements boulimiques dans un journal personnel.

Résultats: On a noté aucun lien entre les divers types de mauvais traitements et la pathologie boulimique. Toutefois, à l'intérieur du groupe boulimique, on a noté une corrélation entre la négligence et les agressions sexuelles d'une part et la pathologie boulimique d'autre part. De plus, on a noté un lien entre une portion des croyances fondamentales et des mauvais traitements vécus en enfance; des profils cognitifs différents s'associent à chaque type de traumatisme.

Conclusions: Les constats devront être interprétés avec soin, étant donné que l'échantillon fut petit et hétérogène. Des recherches plus poussées à l'aide d'échantillons plus considérables et homogènes pourront servir à étudier la mesure dans laquelle ces constats peuvent être généralisés. Ainsi, on pourra déterminer si certains mauvais traitements et croyances fondamentales devraient faire partie d'une thérapie dans de tels cas. De plus, de nouvelles recherches pourraient se pencher sur la relation entre les mauvais traitements, les croyances fondamentales et autres comportements impulsifs.

\section{Resumen}

Objetivo: Este estudio de mujeres bulímicas examinó la relación entre la severidad de maltrato infantil (maltrato emocional, negligencia, maltrato físico, abuso sexual) y la patología bulímica. Además, se investiga la relación del maltrato infantil con la disociación y las creencias centrales.

Método: Una muestra de 23 mujeres con trastornos bulímicos cumplimentaron unas medidas de autoinforme normalizadas sobre el maltrato infantil, la disociación, las creencias centrales y la sintomatología bulímica. También completaron informes diarios de conductas bulímicas.

Resultados: No se observó ninguna relación dimensional entre cualquier forma de maltrato infantil y la patología bulímica. Sin embargo, dentro del grupo de mujeres bulímicas, se observó una correlación entre la presencia de negligencia y abuso sexual y la presencia de sintomatología de disociación. Además, se observó una asociación entre el maltrato infantil y un subgrupo de creencias centrales, con diferentes perfiles cognitivos asociados con cada forma de trauma. 
Conclusiones: Los resultados deben ser interpretados con precaución por el pequeño tamaño de la muestra y su heterogeneidad. Se necesitan desarrollar más investigaciones con muestras más amplias y más homogéneas que permitan analizar la generalizabilidad de estos hallazgos para poder determinar si en tales casos deben tenerse en cuenta desde el punto de vista terapéutico las experiencias particulares de maltrato y las creencias centrales. Además, en investigaciones posteriores se debe considerar la relación entre el maltrato infantil, las creencias centrales y otras conductas impulsivas. 